\title{
A CRÍTICA CULTURAL DE DARCY RIBEIRO*
}

Haydée Ribeiro Coelho

Universidade Federal de Minas Gerais

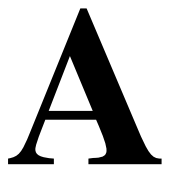

crítica cultural tem sido objeto de inúmeras publicações, temas de congressos, e cursos, ${ }^{1}$ o que tem demonstrado o interesse e a reflexão teórica no enfoque do texto literário, visto não de forma autônoma, mas através de "doações contínuas"2 e de múltiplas imbricações discursivas. A preocupação em inserir o texto literário na cultura não constitui novidade para os enfoques da Teoria Literária. No entanto, o deslocamento do olhar e da enunciação, em relação às teorias produzidas em centro hegemônicos, tem marcado de forma decisiva os estudos culturais no âmbito da América Latina. Sob essa perspectiva, assinalem-se a discussão sobre as epistemologias fronteiriças nos estudos latino-americanos; o interesse em mostrar a tensão entre o local e o global e a abordagem dos temas como o indigenismo no final do século, a identidade, a nação e a globalização.

O contexto descrito explica em parte o interesse crescente pela obra de Darcy Ribeiro, como se pode observar em um texto de Walter Mignolo, divulgado em 1998. ${ }^{3}$ Particularmente, venho estu-dando a

\footnotetext{
"Texto inédito, com algumas modificações, apresentado originalmente durante o "Colóquio Trinacional: A posição da Literatura no Âmbito dos Estudos Culturais", 15 de junho de 1998, Faculdade de Letras, UFMG, Belo Horizonte. ${ }^{1}$ Vejam-se as publicações Revista Iberoamericana, jul./dez. 1996; ANTELO, 1998 e confira-se a realização do 6 ${ }^{\circ}$. Congresso Literatura Comparada, Florianópolis, 1998, cujo tema foi Literatura Comparada: Estudos Culturais. ${ }^{2}$ Cf. SOUZA, 1998, p.189-194.
} 
obra do escritor há muito tempo. Nesse sentido, é impor-tante ressaltar que, na literatura de Darcy Ribeiro, a cultura nunca esteve fora de seus romances. O escritor nunca se furtou a trazer, para a cena do texto, o debate cultural. Além disso, realizou uma ampla reflexão sobre a cultura nacional e sobre a América Latina.

Considerando alguns aspectos aqui esboçados, pode-se dizer que a abordagem da crítica cultural de Darcy Ribeiro suscita várias questões, tais como: noções teóricas que explicitam o conceito de cultura para o autor; o modo como lê a cultura através de uma multiplicidade de olhares e de diferentes estratégias discursivas; o posicionamento diante da cultura, tendo em vista o percurso do escritor como etnólogo indigenista, como educador, como político militante e como ensaísta.

Diante dessas várias dificuldades, esse estudo pretende mostrar, de forma sucinta, alguns aspectos presentes tanto nos textos antropológicos como nos textos literários de Darcy Ribeiro, para que possa situar, ainda que de maneira parcial, suas idéias, no âmbito dos estudos contemporâneos sobre a cultura. O percurso antropoló-gico do escritor não está separado nem de sua militância política nem de sua ficção. Assim, quando se pretende achar o antropólogo, encontramse o político e o ficcionista. Quando se busca o político, depara-se com o intelectual, preocupado em publicar reflexões e memórias sobre o Brasil e sobre a América Latina. ${ }^{4}$

Para o enfoque da crítica cultural de Darcy Ribeiro, três aspectos serão evidenciados: uma visão política da cultura e da Antropologia; uma travessia com Uirá e Em busca da razão latino-americana. No primeiro, situo a concepção que o escritor tem da cultura, considerando algumas questões presentes em O Povo Brasileiro: a formação e o

\footnotetext{
${ }^{3}$ MIGNOLO, 1996, p.91-106. O texto foi divulgado no recente Congresso da ABRALIC, Florianópolis, 1998.

${ }^{4}$ Refiro-me à publicação de Carta, periódico editado pelo Gabinete de Darcy Ribeiro, quando era Senador pelo Estado do Rio de Janeiro até antes de sua morte, 17 de fevereiro de 1997.
} 
sentido do Brasil 5 e em Os Brasileiros: Teoria do Brasil. ${ }^{6}$ No segundo, trato da passagem do escritor da Antropologia para a Literatura, considerando o deslocamento do olhar e da enunciação. O terceiro item procura levar em considera-ção as reflexões sobre a cultura no âmbito da crítica cultural sobre a América Latina.

\section{Uma visão política da Cultura e da Antropologia}

Essas reflexões sobre a cultura iniciam-se com base no livro $O$ Povo Brasileiro pelo fato de o autor considerá-lo como o texto que fecha a série Estudos de Antropologia da Civilização e pela polêmica recente que suscitou, constatada em resenhas críticas na grande imprensa e em periódicos especializados. No âmbito da Antropo-logia, Maurício Andion Arrutti faz um estudo esclarecedor, na medida em que não rechaça simplesmente o texto de Darcy, como "peça academicamente ultrapassada" e o situa criticamente.

O antropólogo começa ressaltando aspectos por que tanto o discurso antropológico como as tendências críticas contemporâneas recusariam O Povo Brasileiro: não parece dialogar com a produção recente; é uma narrativa totalizadora; toma a colonização como parâmetro para desenvolver a forma de ser e de agir do brasileiro. No sentido de mostrar a ausência do diálogo com a produção recente, atesta o uso do conceito de “'transfiguração étnica' associado às noções de processo e de evolução, idéias de bases naturalizantes, acompanhando as formulações neo-evolucionistas de Marvin Harris e Marshal Sahlins, da década de 1960". ${ }^{7}$

Em contrapartida a um "anacronismo inicial" de Darcy Ribeiro, fundamentado em uma "visão totalizante", Maurício Andion Arruti

\footnotetext{
${ }^{5}$ RIBEIRO, 1978.

${ }^{6}$ RIBEIRO, 1995.

${ }^{7}$ ARRUTI, 1995, p.236.
} 
assinala que O Povo Brasileiro coloca a relação entre ciência e política, "Antropologia e colonialismo, questões de grande atualidade", propostas por antropólogos originários de ex-colonias asiáticas e africanas, e mais recentemente, reapropriadas pelos chamados "pósmodernos". Prosseguindo nessa linha de trabalho com as contradições, salienta também como Darcy Ribeiro dá um arranjo novo para elementos tão tradicionais. O tema do livro é a mestiçagem. No entanto, se por um lado essa noção poderia sugerir "Um determinado projeto político social fundado na idéia de branqueamento"; 9 por outro: em $O$ Povo Brasileiro, Darcy Ribeiro visita "o mito para subverter-lhe a narrativa", pois o mestiço, no caso, surge da terra arrasada do vazio de identidade.

Como estudiosa da obra do escritor também me senti instigada pela polêmica que o livro suscitou. No sentido de mostrar como, através desse texto antropológico, a ausência da voz e do olhar do outro na História brasileira é suplementada pela memória ficcional do escritor, procurei fazer um percurso sobre a presença do mito de Maíra com base neste texto e em outros (Uirá Sai à Procura de Deus; Maíra e Diários Índios). Evidenciei que o mito de Maíra ficcionalizado e atualizado na travessia, no romance Maíra, ao ser incorporado também em seu último texto antropológico, deverá, para o autor, fazer parte da memória do povo brasileiro no que ele contém de desmitificador. ${ }^{10}$

A incorporação do mito, em um texto considerado como antropológico pelo escritor, põe em questionamento a escrita da Antropologia brasileira que viu o índio, analisou-o, mas não focalizou o seu olhar, já que esse não teve voz e esteve despojado da letra para falar de si mesmo.

Refletindo sobre algumas questões teóricas levantadas com base na leitura de O Povo Brasileiro, percebo que algumas delas já estão

\footnotetext{
${ }^{8}$ ARRUTI, 1995, p.237.

${ }^{9}$ ARRUTI, 1995, p.238.

${ }^{10}$ COElHO, 1999.
} 
presentes em Teoria do Brasil, cuja primeira edição ocorreu em 1969, no Uruguai.

Nesse livro, escrito no exílio, investigando o processo de formação dos povos americanos, em termos da evolução sócio-cultural, parte de Marx para desenvolver sua teoria. Reconhece que uma das maiores contribuições do filósofo às Ciências Sociais foi a fixação do conceito de "formações sociais". O etnocentrismo de Marx, no entanto, segundo ele, "ao tratar uma linha histórica particular (Escravismo GrecoRomano. Feudalismo Europeu Medieval e Capitalismo Ocidental) o faz como se fosse um paradigma geral da evolução das sociedades humanas". ${ }^{11}$

Com isso, o antropólogo quer dizer que o esquema descrito por Marx, não permite compreender a formação dos povos ameri-canos, em termos de etapas da "evolução sócio-cultural", porque ele não corresponde aos fatos referentes ao mundo extra-europeu e não pode explicá-los. Contrariamente, ao invés de se prender ao modo de produção para estudar as diferentes formações sociais, atém-se aos meios de produção, para traçar os paradigmas americanos. Marx mostra a relação existente entre a história da humanidade e a história da indústria e do intercâmbio e Darcy Ribeiro utiliza-a como categoria para a diferenciação das etapas evolutivas.

Quando o autor usa o termo evolução, pensa-se em um desenvolvimento linear, pois esse conceito, transposto da Biologia, sugere isso. Se se observa, no entanto, o quadro das etapas da evolução sócio-cultural, tendo em vista os paradigmas americanos, vê-se que essa noção se acha modificada pois, através de um quadro apresentado, ${ }^{12}$ o autor procura mostrar como antes da colonização os povos americanos, no caso, tiveram um desenvolvimento econô-micosocial diferente, em decorrência de variadas revoluções tecnológicas. Com a colonização espanhola e portuguesa, os povos americanos,

\footnotetext{
${ }^{11}$ RIBEIRO, 1978, p.29.

${ }^{12}$ RIBEIRO, 1978, p.45.
} 
submetidos ao que ele chama de "atualização histórica", passaram a vivenciar uma progressão homogênea.

No âmbito da discussão das formações sociais, inserem-se dois conceitos básicos no enfoque dos processos civilizatórios: o de "aceleração evolutiva" e o de "atualização ou incorporação histórica". Esses conceitos são importantes aqui, pois estão atrelados à idéia de cultura, objeto de reflexão desse texto e, além disso, são recorrentes na obra antropológica do escritor. No primeiro processo, "o povo ascende de uma a outra etapa evolutiva, preservando a autonomia no comando do seu destino"13 e, no segundo, "é freqüente uma completa traumatização da sociedade avassalada". ${ }^{14}$

O processo civilizatório latino-americano ocorre através da "atualização histórica" ou "incorporação histórica". Nesse caso, as civilizações americanas foram destruídas, "a tal ponto que seus descendentes atuais não puderam conservar a memória do passado". ${ }^{15}$

Enfocando a cultura, Darcy Ribeiro discute as idéias de "cultura genuína" e relativismo cultural. Não aceita a idéia de "cultura genuína" e discute "o relativismo cultural" que conduz à ingenuidade de tratar "certos elementos" da tecnologia moderna como se fossem logros intrinsecamente europeus". ${ }^{16}$ Esse argumento é contestado por ele através da afirmação de que "muitos povos submersos na dependência e no desenvolvimento floresceram no passado como altas civilizações autônomas". ${ }^{17}$ Com base na diferença entre "culturas espúrias" e "cultura autêntica", faz uma critica ao Imperialismo. Essa apóia-se na forma como entende as vias do processo civilizatório e na consciência da desigualdade advinda da exclusão e morte do outro, decorrente das diferentes revoluções tecnológicas, realizadas pelo processo

\footnotetext{
${ }^{13}$ RIBEIRO, 1978, p.43.

${ }^{14}$ RIBEIRO, 1978, p.44.

15 RIBEIRO, 1978, p.47.

${ }^{16}$ RIBEIRO, 1978, p.34.

${ }^{17}$ RIBEIRO, 1978, p.157.
} 
colonizador português e espanhol, na América Latina.

Ainda em Teoria do Brasil, o antropólogo e cientista social faz uma análise das estruturas de poder e enfoca o desenvolvimento econômico-social dos países da América na conjuntura interna-cional.

Inserindo-se em uma tradição voltada para a cultura, de maneira crítica, ressalta como o intelectual brasileiro "raramente explorou os limites de sua consciência possível". Chama a atenção ainda para o fato de a consciência do atraso não ser explicada pelo "papel da espoliação colonial e da exploração patronal como fatores causais de perpetuação da miséria e da ignorância popular". ${ }^{18}$

O destaque à necessidade da consciência crítica do intelectual diante da realidade sócio-econômica vem expresso em diferentes prefácios escritos pelo autor. Ressalto aqui as considerações que faz a respeito de Manoel Bomfim, no prefácio à América Latina; Males de Origem.

Na visão de Darcy Ribeiro, Manoel Bomfim, apesar de ter vivido em Paris em 1903, não se deixou levar pela visão preconcei-tuosa dos europeus em relação aos latino-americanos. Ainda "teve olhos para ver que as teorias do atraso e do progresso que atribuíram ao clima, à raça, à religião católica, são, de fato, teorias urdidas para disfarçar ações hediondas. O que se tomava por sabedoria científica é, a rigor a ideologia do colonizador, consagradora de suas façanhas". ${ }^{19}$

Tendo em vista as posições apresentadas aqui, Darcy Ribeiro mostra, em seu discurso, que a esfera cultural, segundo Edward Said, "tida como livre e incondicionalmente disponível para etéreas investigações e especulações teóricas" e a esfera política vista como o lugar "onde se supõe ocorrer a verdadeira luta de classes" ${ }^{20}$ estão não apenas relacionadas, mas são as mesmas.

A obra antropológica do escritor é vasta e os conceitos teóricos

\footnotetext{
${ }^{18}$ RIBEIRO, 1978, p.157.

${ }^{19}$ RIBEIRO, 1993, p.12.
} 
usados por ele migram de um texto para outro. O que se buscou até aqui é mostrar que Darcy assume uma posição política em relação aos seus escritos sobre a cultura e não só se apropria de conceitos tradicionais, dando-lhes "novos arranjos", como evidenciou Maurício Andion, mas também modifica conceitos para refletir sobre a cultura brasileira conceitos tidos como etnocêntricos, incapazes de refletir sobre a cultura brasileira.

\section{Uma travessia com Uirá}

Essa forma crítica de posicionar-se na Antropologia, sob uma dimensão política e a partir do contexto em que se insere, pode ser percebida também em Uirá sai à procura de Deus, texto de 1957, que a meu ver realiza a travessia do autor da Antropologia para a Literatura. Aqui já se insinuam aspectos que a Antropologia Pós-moderna hoje problematiza: a noção de centramento da palavra pelo antropólogo. ${ }^{21}$

Sob a perspectiva antropológica, Lúcia Helena Rangel e Cláudia Izique, ao resenharem o livro, assinalaram a contribuição indispensável trazida por ele, "para a formação de uma visão mais justa a respeito da questão indígena que ameaça emergir". ${ }^{22}$

Recolhendo as diversas fontes para a construção do seu texto antropológico, Darcy Ribeiro introduz olhares diferenciados: o da cultura do branco, o da cultura do índio e do antropólogo, situado entre duas culturas. Nesse texto, ao evidenciar esses olhares, visualiza para o leitor esse momento trágico da opção de Uirá:

Figuremos Uirá, magnífico em seus adornos, o corpo pintado, à imagem do herói mítico, armas à mão, a tensão de quem enfrenta a mais terrível prova expressa no rosto, nos gestos. Assim deveria parecer à mulher e aos filhos, aos olhos de sua gente. ${ }^{23}$ (Os grifos são meus).

\footnotetext{
${ }^{20}$ SAID, 1995, p.93.

${ }^{21}$ CALDEIRA, 1988.

${ }^{22}$ RANGEL e IZIQUE, 22 abr. 1978.
} 
A ficcionalização, que pode ser percebida através desse fragmento, não só acena já nesse momento (1957, data da publicação de Uirá sai à procura de Deus) para a necessidade de ruptura com um único olhar sobre o outro, como também já prenuncia um deslocamento da enunciação que irá acontecer, de outra forma, anos mais tarde, em1976, quando o autor se inaugura como ficcionista, com a publicação de Maíra.

Pela ficção, através dos personagens, o autor coloca diferentes máscaras, vivenciando várias espacialidades; incorpora a oralidade na fala de seus personagens; dialoga com textos que pertencem tanto à tradição antropológica como a tradição literária brasileira e européia; redimensiona a questão da identidade indígena através da voz e do olhar do índio (que está presente em Uirá, mas que se intensifica em Maíra, através da enunciação). Justapõe tempos e culturas diferentes; fala das relações de poder através da ironia e do humor; rompe com uma visão binária, presente na utilização de uma determinada terminologia antropológica (como aquelas de "cultura espúria" e "cultura autônoma"); trata da utopia através do entrecru-zamento discursivo; incorpora a antropofagia de Oswald, abrigando-a em outros contextos históricos. (Maíra e Utopia Selvagem).

O espaço tem uma importância fundamental na obra do escritor, permitindo-lhe realizar um projeto mais amplo. Esse aspecto está esboçado no livro que organizei sobre Darcy Ribeiro. ${ }^{24}$ A travessia, metáfora que Eduardo Coutinho ${ }^{25}$ utiliza, para configurar a narrativa latino-americana como expressão da busca da identidade, se estende aos textos do romancista, possibilitando-lhe romper com uma visão marcada pelo binarismo. No caso de Maíra não se trata de uma simples oposição, mundo indígena versus mundo do branco, mas o entrecruzamento entre os mundos, como enfatizou recentemente

${ }^{23}$ RIBEIRO, 1976, p.25.

${ }^{24}$ COELHO (Org.), 1997, 194p.

${ }^{25}$ COUTINHO, 1998, p.15-23. 
Antonio Candido. ${ }^{26}$

Estudando a crítica sobre Darcy Ribeiro, percebe-se que o autor, ao longo dos anos, através de entrevistas e de comentários sobre sua obra, torna-se um leitor a mais de seus textos. Assim em Confissões, na parte relativa aos romances, o escritor declara que Utopia Selvagem retrata o Brasil e a América Latina. Além desse comentário e de outros igualmente importantes a propósito da fábula, chama-nos a atenção o modo como Darcy Ribeiro incorpora a linguagem midiática e burocrática à sua ficção. Acena-nos para o fato de que a compreensão da identidade latino-americana não pode ignorar o contexto histórico a que se reporta. Publicado em 1982, a fábula mostra, de forma tensa, o Brasil e a América letrados; o Brasil e a América indígenas, o Brasil e a América midiáticos.

No plano ficcional, a fábula apresenta uma das cenas da vida pósmoderna cujas imagens podem ser reconhecidas nas descrições de Beatriz Sarlo, no capítulo atinente ao "zapping". O ficcionista, ao abusar dos recursos visuais, faz com que o leitor, através de um organograma, reconheça/estranhe as representações de Próspero (multinacionais) e de Calibã (brasileiros). Nesse contexto, cada "utopiano tem implantado no pulso esquerdo um Televisor Ecumênico (TVE) e um canal Fidebeque (CF)", ${ }^{27}$

Essa idéia de refletir sobre o Brasil no contexto da América Latina acha-se já bastante presente na obra antropológica do escritor. Ressaltem-se aqui os livros O Dilema da América Latina, As Américas e a Civilização e em Ensaios Insólitos ("A América Latina existe?", "Tipologia política latino-americana").

Nos anos 90, uma das formas de atualizar o debate político sobre o Brasil e a América Latina, ocorre através de Carta, publicação feita pelo Gabinete de Darcy Ribeiro, quando ocupava o cargo de senador até 1997, data de seu falecimento.

\footnotetext{
${ }^{26}$ CANDIDO, 1996, p.381-385.

${ }^{27}$ RIBEIRO, 1982, p.152.
} 
Carta compõe-se de falas, reflexões e memórias. Em referência à América Latina, são divulgados textos diversos. No campo da Antropologia, da Economia e da Política, ressaltem-se os textos "La integración Latinoamericana", de Leopoldo Zea; "O fim da guerra fria e a América Latina" de Celso Furtado e "A América Latina sobreviverá" de Aníbal Quijano, dentre outros. Na cena do debate político, coloca em discussão a integração da América Latina, idealizada com base no econômico pelos representantes do neoliberalismo.

Poder-se ia pensar que sua obra literária seria a reduplicação de seus escritos antropológicos. Longe disso, pois é justamente a consciência de que as criações literárias oferecem "amplos painéis das condições de existência do povo e profundas percepções do espírito brasileiro, incomparavelmente melhores que toda a produção ensaística"28 que motiva o escritor, dentre outras razões, a fazer o trânsito para a Literatura.

\section{Em busca da razão latino-americana}

Em "O movimento dos conceitos na Antropologia", Roberto Cardoso de Oliveira situa a Antropologia periférica ("aquela praticada fora da Inglaterra, França e Estados Unidos") com um sujeito epistêmico singular, pois não estuda "um outro transoceânico e distante, mas um outro interno e próximo". ${ }^{29}$ Esse enfoque implica um compromisso ético com a construção da nação, manifesto através do indigenismo que caracteriza o desenvolvimento da Antropologia em toda a América Latina. No âmbito antropológico, essas considerações estendem-se a Darcy Ribeiro. Em seus vários textos tanto antropológicos como literários, Darcy não somente estuda "o outro interno e próximo", mas se vale de diferentes estratégias discursivas para apresentar o "outro".

\footnotetext{
${ }^{28}$ RIBEIRO, 1978, p.14.

${ }^{29}$ OLIVEIRA, 1994, p.13.
} 
Sob a perspectiva cultural latino-americana, Santiago CastroGómez ressalta como o semiólogo Walter Mignolo faz uma releitura da tradição da filosofia latino-americana "a partir da discussão póscolonial". ${ }^{30}$ Nesse contexto de considerações sobre o pensamento desse autor, Santiago Castro-Gómez mostra que, nesse caso, a crítica ao imperialismo, ao invés de trabalhar com o paradigma da alteridade, se volta agora para abordar "como os sujeitos subalternos têm canibalizado o discurso europeu, criando a partir dele, um lugar próprio de enunciação. ${ }^{31}$

Em Walter Mignolo (1996), ao refletir sobre os espaços geográficos e localizações sob uma perspectiva não eurocêntrica, constata a "inversão epistemológica que marca a inserção do pósocidental-colonial imperial nos Estados Culturais". ${ }^{2}$ Ao tratar de uma epistemologia fronteiriça que promove formas de conhecimento produzidas nas regiões de legados coloniais, evidencia como Darcy Ribeiro exemplifica essa epistemologia fronteiriça pois, "incorpora a civilização à barbárie, ao mesmo tempo em que nega o conceito colonial hegemônico". ${ }^{33}$ Essa percepção da singularidade da obra antropológica de Darcy Ribeiro, voltada para uma reflexão sobre a diversidade regional latino-americana, encontra-se presente também em Transculturación narrativa em America Latina de Angel Rama. ${ }^{34}$

Nesse estudo, procurei ressaltar aspectos suscitados por alguns textos antropológicos de Darcy Ribeiro. Além da importância de sua obra antropológica, o texto literário permite ao autor outras veredas.

${ }^{30}$ CASTRO-GÓMEZ, 1996, p.149. Tradução livre.

${ }^{31}$ CASTRO-GÓMEZ, 1996, p.149. Tradução livre.

32 MIGNOLO, 1996. p.93.

${ }^{33}$ MIGNOLO, Walter, 1996, p.98.

${ }^{34}$ RAMA, 1989. Agradeço à Profa. Dra. Eneida Maria de Souza que, no momento do debate, durante o Colóquio Trinacional, atentou-me para o relaciona-mento entre o conceito de cultura segundo Darcy Ribeiro e aquele de transculturação de Fernando Ortiz, enfocado por Angel Rama. 
Essa abrangência decorre, em parte, do uso das mais diferentes estratégias discursivas que pode lançar mão no discurso ficcional. Nesse sentido, pode-se dizer que a obra do escritor brasileiro permite mostrar o discurso europeu canibalizado, a partir de um lugar próprio de enunciação.

A palavra, a ser lavrada pelo crítico da cultura, se alça como um desafio. Depois de ter publicado Diários Índios, o autor, em uma entrevista concedida à Folha de S. Paulo, diz o seguinte:

Achava que tinha de extrair deles um texto teorizante (...) É assim que a Antropologia trabalha. Converte tudo em coisa genérica. O genérico não há. O que existe é cada casamento, cada batizado, marcado por suas circunstâncias. ${ }^{35}$

Por mais que Darcy falasse sobre seu percurso, e teorizasse sobre o povo brasileiro, sua obra dispersa em tantos textos, com certeza, tem muito a contribuir para a crítica ou a razão latino-americana. Sua obra antropológica e literária tem vários matizes e oferece diferentes veredas.

A análise do entrecruzamento de olhares e de vozes diante da cultura talvez seja um caminho para situar Darcy Ribeiro, no âmbito das discussões contemporâneas sobre a cultura e sobre a razão latinoamericana. Ao compor "espelhos para nos ver", nossas imagens projetam-se, de maneiras múltiplas, nos espelhos do escritor, "artífice do jogo de construção simbólica” ${ }^{36}$ Como artífice desse jogo, não fala de um lugar neutro, porém marcado pelo Marxismo, pelo exilio e como político no cenário brasileiro. Esse é outro aspecto que merece ser trilhado, aprofundando o relaciona-mento entre a cultura e a nação.

${ }^{35}$ Anotações para o ano 3000. Entrevista concedida a Otávio Dias, Folha de S. Paulo, São Paulo, 11 ago. 1995, Caderno Mais, p.5.

${ }^{36}$ ORTIZ, 1982, p.142. 


\section{Referências Bibliográficas}

ANTELO, Raul et al (Org.). Declínio da arte. Ascensão da cultura. Florianópolis: Obra Jurídica, 1998.

ARRUTI, José Maurício Andion. A narrativa do fazimento ou por uma Antropologia brasileira. Novos Estudos CEBRAP, São Paulo, n.43, nov. 1995.

CALDEIRA, Tereza Pires do Rio. A presença do autor na pósmodernidade em Antropologia. In: Novos Estudos CEBRAP. São Paulo, n.21, jul. 1988.

CANDIDO, Antonio. Mundos cruzados. In: RIBEIRO, Darcy. Maíra: um romance dos índios e da Amazônia. 15. ed. Rio de Janeiro: Record, 1996.

CASTRO-GÓMEZ, Santiago. Critica de la razón latinoamericana. Barcelona: Puvill Libros, 1996.

COELHO, Haydée Ribeiro (org.). Darcy Ribeiro. Belo Horizonte: Centro de Estudos Literários da UFMG, Curso de Pós-Graduação em Letras - Estudos Literários, 1997.

COELHO, Haydée Ribeiro. O mito e suas encruzilhadas. In: MARI, Hugo et al. Fundamentos e dimensões da análise do discurso. Belo Horizonte: Carol Borges, 1999.

COUTINHO, Eduardo. A busca da terceira margem do rio: a questão da identidade cultural na narrativa latino-americana contempo-rânea. In: I Seminário Internacional Latino-americano de Literatura Comparada. Porto Alegre: UFGRS, 1986.

MIGNOLO, Walter. 5, Associação Brasileira de Literatura Comparada, 5, 1996. Cânones e contextos. Rio de Janeiro: Faculdade de Letras, 1996. v.1, p.91-106.

MORAÑA, Mabel (Org.). Revista Iberoamericana. Crítica cultural y teoría literaria latinoamericanas, Pittsburg, v.62, n.176-177, 1996.

OLIVEIRA, Roberto Cardoso. O movimento dos conceitos na Antropologia. Revista de Antropologia. São Paulo, Departamento de Antropologia, Fac. de Filosofia, Letras e Ciências Humanas, USP, n.36, 1994. 
RAMA, Angel. Transculturación narrativa em América Latina. Montevideo: Arca Editorial, 1989.

RANGEL, Lúcia Helena e IZIQUE, Cláudia. Em busca do herói civilizador. F. de São Paulo, São Paulo, 22 abr. 1978.

Revista Iberoamericana. Crítica cultural y teoría literaria latinoamericanas, Pittsburg, v.62, n.176-177, jul./dez. 1996.

RIBEIRO, Darcy. Uirá sai à procura de Deus. Ensaios de Etnologia e Indigenismo. 2. ed. Rio de Janeiro: Paz e Terra, 1976.

RIBEIRO, Darcy. Os brasileiros: Teoria do Brasil. Petrópolis: Vozes, 1978.

RIBEIRO, Darcy. Manoel Bomfim, antropólogo. In: BOMFIM, Manoel. A América Latina. Males de origem. Rio de Janeiro: Topbooks, 1993.

RIBEIRO, Darcy. Anotações para o ano 3000. Entrevista concedida a Otávio Dias, Folha de S. Paulo, São Paulo, 11 ago. 1995. p.5.

RIBEIRO, Darcy. Opovo brasileiro. A formação e o sentido do Brasil. São Paulo: Companhia das Letras, 1995.

SAID, Edward W. Cultura e imperialismo. Trad. Denise Bottman. São Paulo: Companhia das Letras, 1995.

SOUZA, Eneida Maria de. Os livros de cabeceira da crítica. In: ANTELO, Raul et al. Declinio da arte; ascensão da cultura. Florianópolis: Obra Jurídica, 1998. 


\section{Resumo}

Esse ensaio apresenta, de forma sucinta, alguns aspectos que se relacionam a textos antropológicos e literários de Darcy Ribeiro. Tem como objetivo situar as idéias do escritor no contexto dos estudos culturais contemporâneos. Para isso, focaliza a perspectiva política do autor diante da cultura e a passagem do escritor da Antropologia para a literatura, através da publicação de Uirá sai à procura de Deus.

Para concluir, aborda também as idéias do autor no contexto da razão latino-americana.

\section{Résumé}

Cet essai présente, sous la forme succinte, quelques aspects qui se rapportent aux textes anthropologiques et littéraires de Darcy Ribeiro. Il a pour but de situer les idées de l'écrivain là dans le contexte des études culturelles contemporaines. Pour cela, on envisage la perspective politique de Darcy Ribeiro devant la culture et devant la Anthropologie et aussi le trajet de l'écrivain de l'Anthropologie à la littérature à travers de la publication de Uirá sai à procura de Deus.

Pour concluire, on examine aussi des idées du l'anthropologue dans le contexte de la raison latino-américaine. 